В статье рассмотрены результаты деятельности образовательно-научного центра «Менеджмент» (ОНЦМ) новой формы управления профильными кафедрами и взаимодействия с факультетами. Выбор данной организационной формы в РЭУ им. Г. В. Плеханова был стратегически верным, что подтверждается майскими указами 2018 г. Президента Российской Федерации. Формирование лидерских позиций университета в подготовке студентов по направлению «Менеджмент» обеспечивается интеграцией и координацией совместных действий управленческой команды ОНЦМ, преподавателей и сотрудников кафедр, научных школ, НИИ и других структурных подразделений. Проиллюстрированная авторами статьи динамика организационной структуры ОНЦМ обусловлена направленностью на решение ежегодных программных задач развития университета. Создание базовых кафедр и научно-исследовательских лабораторий позволяет интегрировать учебный процесс с реальной практикой менеджмента, что подтверждается международной и профессионально-общественной аккредитацией образовательных программ. Из 20 основных профессиональных образовательных программ подготовки бакалавров и магистров по менеджменту 6 имеют аккредитацию Европейского совета по бизнес-образованию (ЕСВЕ) и 13 - профессионально-общественную. Востребованность программ подготовки по направлению «Менеджмент» обеспечивается комплексом проводимых работ, среди которых авторы отмечают системную профориентацию выпускников ведущих московских школ, партнерство с Региональным центром профориентации и трудоустройства на базе Земской гимназии городского округа Балашиха, использование современных образовательных технологий, реализацию двуязычных программ и др. Научной новизной статьи является критическое осмысление проблем и перспектив формирования лидерских позиций подготовки студентов по направлению «Менеджмент» на основе комплексного анализа деятельности ОНЦМ, рассмотрения влияния проводимых реформ образования на результаты деятельности университетов. Авторы дают ряд рекомендаций по достижению лидерских позиций при подготовке студентов по направлению «Менеджмент».

Ключеbые слова: лидерство, проектный метод, цифровизация образования, тотальный менеджмент качества, стратегия прорыва, качество подготовки, интеграция.

\title{
CHALLENGES AND PROSPECTS OF SHAPING THE LEADING POSITIONS OF THE PLEKHANOV RUSSIAN UNIVERSITY OF ECONOMICS IN TRAINING STUDENTS FOR SPECIALIZATION 'MANAGEMENT'
}

\author{
Mikhail N. Kulapov, Valeriy V. Maslennikov, \\ Maksim A. Ponomarev, Liliya S. Babynina \\ Plekhanov Russian University of Economics, Moscow, Russia
}

The article provides results of the education and scientific center 'Management' work (OSCM), a new form of managing the profile chairs and interaction with faculties. The choice of this organizational form in the Russian Plekhanov University of Economics was correct, which is proved by May 2018 Decrees of the President of the 
Russian Federation. Shaping the leading positions of the university in training students for specialization 'Management' is ensured by integration and coordination of joint efforts of the OSCM managerial team, lecturers and employees of chairs, academic schools, research institutions and other structural divisions. Dynamics of the OSCM organizational structure shown by the authors is stipulated by focusing on resolving yearly program objectives of university development. Founding key chairs and research labs provides an opportunity to integrate the teaching process with the real practice of management, which is confirmed by international and professionalpublic accreditation of education programs. There are 20 key professional education programs of training bachelors and masters of management, 6 of them were accredited by the European Council on Business Education and 13 have professional- public accreditation. The demand for training programs for specialization 'Management' is provided by the whole set of measures, including system career advising of Moscow school leavers, partnership with the Regional Center of career advising and employment based in the Zemskiy gymnasia in Balashikha, the use of advanced education technologies and two-language programs, etc. The academic novelty of the article is connected with its critical comprehension of challenges and prospects of shaping leading positions in training students for specialization 'Management' on the basis of OSCM work analysis, studying the impact of current reforms on the university functioning. The authors put forward a number of recommendations dealing with the goal of attaining leading positions in training students for specialization 'Management'.

Keywords: leadership, project method, education digitalization, total quality management, break-through strategy, training quality, integration.

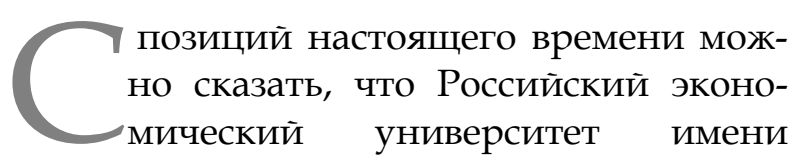

Г. В. Плеханова осуществил форсайт механизмов интеграции научной и образовательной деятельности в форме образовательно-научных центров. Подобным центрам дан старт майскими указами 2018 г. Президента В. В. Путина, предусматривающими создание сети 15 научно-образовательных центров мирового уровня в России [10].

Новые формы взаимодействия науки, преподавательской деятельности и бизнеса обеспечивают гибкость организационных структур и эффективную их адаптацию к быстро меняющимся условиям. Они становятся производственными единицами, обеспечивая интеграцию и координацию совместных действий, решая проблемы, которые станут актуальными через 10 и более лет. Эффективный обмен ресурсами, благоприятные условия для разработки и внедрения продуктово-технологических и организационно-управленческих инноваций позволяют укрепить научный и образовательный потенциал университета [1. C. 21].

Сама по себе задача достижения лидерства вуза в том или ином направлении опирается на стратегию самого вуза и тактику его поведения по основным направлениям деятельности [3. - С. 117-123].
Завоевание лидерских позиций университета и его структурных подразделений достигается на основе решения ежегодных программных задач, предполагающих системную работу с организационной структурой и кадровым составом. Для этого поступательно совершенствуется состав включенных в образовательно-научный центр управленческих кафедр и научных подразделений, а также формируется общая предметная область деятельности по направлению «Менеджмент» [8. - С. 94].

Новым вектором обсуждения проблем интеграции вузов и организаций реального сектора стал вопрос о создании и функционировании базовых кафедр университета, которые рассматриваются как инструмент усиления практико-ориентированной направленности учебного процесса. Поэтому создание базовых кафедр в составе ОНЦМ позволяет результативно выполнять научные исследования и развивать образовательные программы в соответствии с реальными потребностями практики и запросами работодателей (рис. 1).

Важным шагом стала реализация совместных проектов с ФАС России и ООО «Капитал Групп»: были созданы базовая кафедра ФАС России и базовая кафеера «Управление проектами и программами Capital Group». В настоящее время работа над созданием базовых кафедр продолжа- 
ется в соответствии с соглашениями о сотрудничестве между Российским экономи-

2017-2018

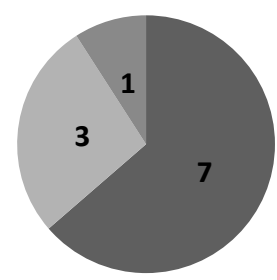

ческим университетом имени Г. В. Плеханова и работодателями.

2018-2019

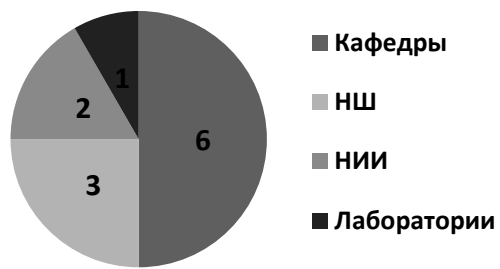

Рис. 1. Динамика развития структуры ОНЦМ

Открытие научно-исследовательской лаборатории «Виртуальные цифровые продукты», которая представляет собой междисциплинарный исследовательский и ресурсный центр, направлено на реализацию задач майских указов 2018 г. Президента Российской Федерации и программы «Цифровая экономика Российской Федерации». Интеграция результатов научно-исследовательской и образовательной деятельности по направлению «Менеджмент» основана на создании обучающих тренажеров, симуляторов, имитационных деловых игр с использованием цифровых технологий. Такие образовательные продукты позволяют коммерциализировать результаты интеллектуальной деятельности в реальном секторе экономики и повысить привлекательность программ.

Новые организационные формы при реализации стратегических целей университета по усилению лидерских позиций развиваются в партнерском контакте с факультетами, осуществляющими подготовку студентов по направлению «Менеджмент». Это взаимодействие прежде всего касается качества образовательных программ. В на- стоящее время в ОНЦМ кафедрами реализуется 6 основных профессиональных образовательных программ (ОПОП), получивших международную аккредитацию Европейского совета по бизнес-образованию (ЕСВЕ). В 2019 г. подана заявка на международную аккредитацию всех реализуемых программ на факультете менеджмента.

В 2018/19 учебном году кафедрами ОНЦМ реализовано 20 основных профессиональных образовательных программ (11 бакалаврских и 9 магистерских), 13 из которых имеют профессионально-общественную аккредитацию от объединений работодателей: Вольного экономического общества России (ВЭО), Агентства по контролю качества образования и развитию карьеры (АККОРК), Ассоциации менеджеров, Профаккредагентства «Опора РосСИИ».

Практико-ориентированность образовательных программ достигается на основе системной работы по профориентации и организации практики, обеспечивающей позитивную динамику приема на факультет менеджмента в период 2016-2018 гг. (рис. 2).

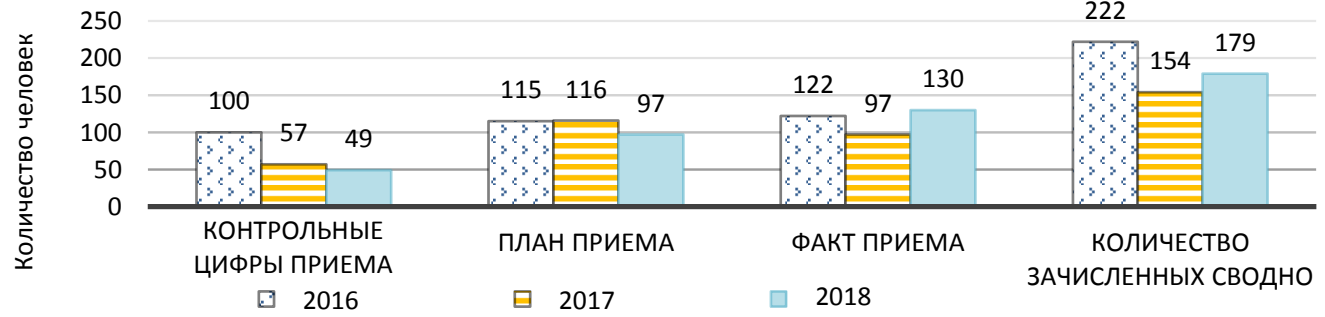

Рис. 2. Сравнительные итоги приема на факультет менеджмента в 2016-2018 гг. 
В 2016-2018 гг. отмечалась позитивная динамика приема на ОПОП бакалавров по направлению «Менеджмент» на всех факультетах университета при снижении числа студентов бюджетного набора и одновременном росте фактического внебюджетного набора (рис. 3).

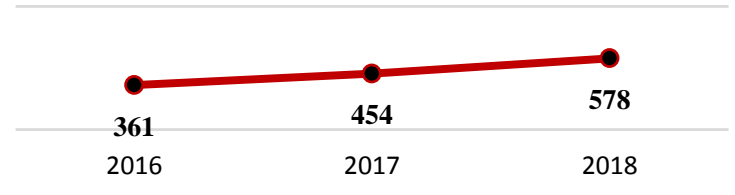

Рис. 3. Общий прием на ОПОП бакалавров по направлению «Менеджмент» в РЭУ им. Г. В. Плеханова (в чел.)

Перевыполнение планов приема одновременно сопровождается улучшением качества знаний абитуриентов на основе среднего балла ЕГЭ при бюджетном и внебюджетном наборе. Для сравнения, в 2016 г. средний балл ЕГЭ студентов, зачисленных на внебюджетную форму обучения по направлению «Менеджмент», составлял 65,7; а в 2018 г. - уже 70,6.

Востребованность программ подготовки по направлению «Менеджмент» и рост качественных характеристик абитуриентов позволили за два года повысить позиции университета с 12-го до 5-го места в рейтинге по качеству приема при росте среднего балла ЕГЭ в 2016-2018 гг.

В значительной степени росту рейтинга способствовали креативно-системный подход к организации занятий со школьниками и проведение профориентационных мероприятий с Региональным центром профориентации и трудоустройства РЭУ им. Г. В. Плеханова на базе Земской гимназии городского округа Балашиха и с ведущими московскими школами.

На этапе выбора будущей профессии вовлечение школьников в реальные бизнес-ситуации в проекте «Школа юного управленца», включение в традиционные факультетско-кафедральные мероприятия (международные бизнес-недели, олимпиады и кейс-чемпионаты по менеджменту, проведение комплексного дискуссионного клуба абитуриентов по китайской тематике) позволяют им осознанно подойти к выбору направления подготовки в университете.

Поколение подрастающих школьников будущих абитуриентов не представляет своей жизни без гаджетов и общения в социальных сетях, имеет устойчивые навыки использования цифровых технологий, Интернета и мобильных приложений. Для них доступны образовательные онлайнресурсы международных и российских вузов, что усиливает конкуренцию в образовательной среде. В работе с «поколением гаджетов» исключительно важным шагом к лидерству в направлении менеджмента представляется адаптация образовательных продуктов под требования цифровизации.

Использование информационно-коммуникативных технологий (ИКТ) приводит к изменению методов выполнения работы, что вызывает повышение спроса на комплементарные ИКТ-навыки (complementary skills), поддерживающие выполнение новых задач, связанных с использованием этих технологий на рабочем месте. Например, к ним относятся использование социальных сетей для коммуникации с коллегами и клиентами, продвижение бренда продуктов на платформах электронной коммерции, анализ больших данных, бизнес-планирование и др., которые стали частью современных управленческих систем во многих видах экономической деятельности. Формирование таких междисциплинарных навыков у будущих менеджеров предусматривает изифровизацию образовательных продуктов, мотивирующих студентов к усвоению учебных материалов и обеспечивающих большую результативность.

ИКТ и методы проектного обучения реализуются в онлайн-курсах «Проектирование бизнеса» (на платформе UNIWEB), «Цифровой менеджмент», «Умный рюкзак», «Анализ и прогнозирование временных рядов». Партнерские отношения с бизнесом расширяют возможности исполь- 
зования информационных технологий в учебном процессе. Например, компания Bentley Systems Inc. предоставила базовой кафедре «Управление проектами и программами Capital Group» программный продукт «Информационное моделирование (BIM) в управлении проектами строительства и ЖКХ» для учебной деятельности. Учебные задания и их выполнение становятся увлекательными при подготовке студентами видеороликов по результатам выполненных учебных проектов или научно-исследовательской работы. Такие подходы к обучению, используемые преподавателями, владеющими ИКТ на высоком уровне, поддерживаются и получают развитие в программах подготовки бакалавров и магистров.

Лидерские позиции университета по направлению «Менеджмент» определяются международным признанием научных исследований по методике британской компании Quacquarelli Symonds (QS). Meтодика QS в предметном и отраслевом рейтинге предусматривает расчет индикаторов академической репутации, количества цитирований на одну публикацию и индекса Хирша. Значительный рост количества публикаций ОНЦМ в 2017 г. отражает изменение тактических задач программы развития РЭУ им. Г. В. Плеханова для достижения целевых показателей меж- дународных рейтингов. Так, количество публикаций в базе Scopus выросло на 23\% по сравнению с 2016 г., в WoS - почти в 3 раза. Однако следует отметить, что рост количественных показателей не означает автоматического повышения качества публикуемых статей. Качественный рост - это публикации в высокорейтинговых журналах и увеличение числа высокоцитируемых авторов. По ежемесячным данным РИНЦ, численность научно-педагогических работников ОНЦМ среди 100 наиболее цитируемых сотрудников университета в 2017 г. составила 19 человек, в 2018 г. 21 человек, в 2019 г. - 24 человека, что отражает постепенное улучшение качественных показателей.

Образовательная и научно-исследовательская деятельность, имеющая признание на международном и национальном уровне, обеспечивает ресурсную базу для дальнейшего развития университета и его структурных подразделений. Формирование механизма управления и коммерциализации результатов интеллектуальной деятельности, полученных в ходе выполнения научно-исследовательских работ (НИР) и программ дополнительного профессионального образования (ДПО), позволило значительно увеличить совокупные доходы ОНЦМ в 2018 г. по сравнению с 2016 г. (рис. 4).

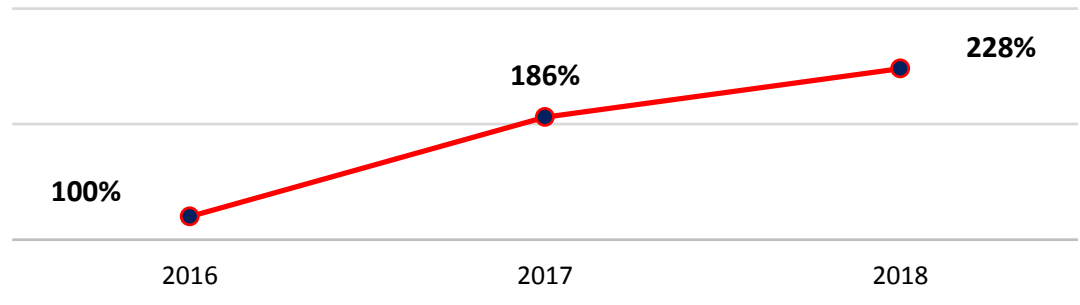

Рис. 4. Рост фактических доходов ОНЦМ от НИР и ДПО

Вместе с тем вклад структурных подразделений в общие результаты деятельности ОНЦМ существенно различается. Обеспечение выполнения планов НИР достигается подачей заявок на внешние конкурсы и выполнением хоздоговорных работ. Так, в 2016 г. из 64 поданных заявок на внешние конкурсы НИР было выиграно 3; в 2017 г. это соотношение составило 30 к 4; в 2018 г. - 26 к 2. Трудоемкость оформления подачи заявок на внешние конкурсы и эффект от выигранных заявок оказываются несопоставимыми. Поэтому умение правильно представить свои достижения в науке во 
многом определяется лидерскими качествами руководителей (заведующих кафедрами, директоров НИИ, руководителей научных школ), компетентностью, профессионализмом НПР и их амбициями в достижении поставленных целей при взаимодействии с представителями бизнеса. Только в этом случае, по мнению авторов, можно обеспечить коммерциализацию научно-исследовательских работ и дополнительного профессионального образования.

Другими направлениями развития научной деятельности являются ежегодно проводимые кафедрами ОНЦМ научные конференции, позволяющие вовлекать абитуриентов и студентов в сбор материалов для выполнения НИР, тем самым способствуя развитию их аналитических способностей. Размещение в социальных сетях результатов научных исследований, выполненных под руководством ученых совместно со студентами, повышает мотивацию к продолжению совместных исследований и обеспечивает их доступность абитуриентам, выбирающим для своей будущей подготовки направление «Менеджмент».

Международную деятельность ОНЦМ развивает совместно с факультетами в тесном сотрудничестве с управлением международной деятельности университета в направлении реализации программ двойного диплома и обмена, мобильности преподавательского состава. Кафедры ОНЦМ реализуют две программы на английском языке и две программы двойного диплома. В целях развития совместных образова- тельных программ с ведущими российскими и иностранными университетами и научными организациями проводятся переговоры с университетами Германии, Чехии, Финляндии (университет Лауреа, университет Сатакунта). Устанавливаются партнерские отношения с Рижским техническим университетом (Латвия), с Фондом «Национальный университет архитектуры и строительства Армении» (Республика Армения, Ереван), Белорусским государственным университетом, Байкальским институтом природопользования СО РАН. Заключено рамочное соглашение с институтом Поля Бокюза (Франция) о реализации совместных программ подготовки бакалавров и магистров.

Качество образовательно-научной деятельности современного университета зависит в первую очередь от квалификаиии профессорско-преподавательского состава (ППС). Реализуя свою стратегию, ОНЦМ уделяет значительное внимание улучшению качественного состава ППС в направлении роста их компетентности и профессионализма. Подготовка ППС к профессиональной деятельности осуществляется в традициях российской высшей школы и обеспечивается реализацией следующих мероприятий: повышением квалификации, участием в школах молодых преподавателей и молодых исследователей с последующим включением в кадровый резерв, привлечением внешних перспективных преподавателей из филиалов университета и других вузов, развитием международной мобильности и др. (рис. 5).

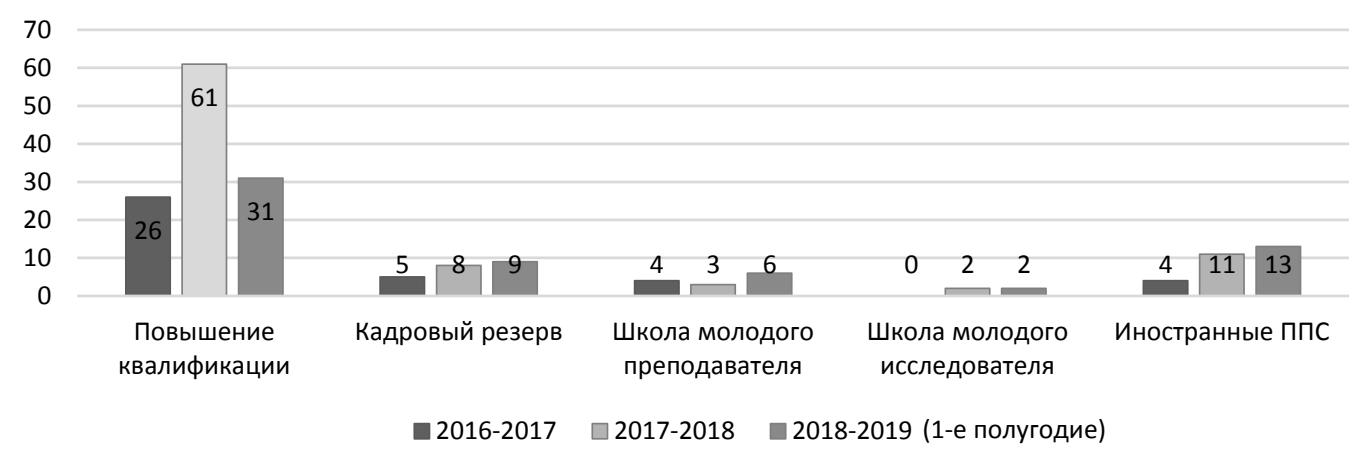

Рис. 5. Развитие ППС кафедр ОНЦМ 
Повышение качества высшего образования возможно только при условии активного участия работодателей в образовательном процессе. С этой целью организуются мастер-классы и гостевые лекции, стажировки преподавателей в компаниях бизнеспартнеров, проводятся выездные занятия со студентами на базе конкретных организаций по направлению «Менеджмент».

Количественный состав ППС кафедр ОНЦМ менялся в соответствии с тактическими задачами университета, поставленными перед всеми структурными подразделениями. Для соблюдения утвержденных в университете требований к ППС при подаче документов в конкурсную комиссию проводится тщательный их анализ секретарем совета ОНЦМ и используются административно-организационные и мотивационные методы по недопуску к конкурсному избранию ППС, не выполняющих показатели своего развития. Эти меры обеспечили рост доли ППС со степенью на кафедрах ОНЦМ с 81,3\% в 2016/17 учебном году до 90,5\% в 2018/19 учебном году.

В настоящее время численность ППС кафедр ОНЦМ составляет 153 человека, из них основной штатный состав - 108 человек, внутренние совместители - 24 человека, внешние совместители - 21 человек. Стратегическая цель по повышению международных рейтингов университета и соблюдение требований ФГОСов предусматривают привлечение иностранных преподавателей и преподавателей-практиков из реального бизнеса. Однако их оформление на работу в университет осложняется бюрократическими процессами: необходимо получение справки об отсутствии судимости, прохождение конкурсных процедур избрания на должность, а также обеспечение баланса мощности кафедр и нагрузки. Перед заведующими кафедрами возникают риски невыполнения этого баланса, что решается в ряде случаев переводом штатных преподавателей на долю ставки. Несмотря на указанные проблемы, организационно-управленческие решения в ОНЦМ обеспечили рост показателей по привле- чению иностранных преподавателей в 3,2 раза в 2018/19 учебном году по сравнению с 2016/17 учебным годом.

Партнерское сотрудничество ОНЦМ с факультетами и управлениями университета обеспечило повышение международного рейтинга по направлению «Менеджмент». В 2017 г. впервые РЭУ им. Г. В. Плеханова вошел в рейтинг по предметной области «Общественные науки и управление» (социальные науки и менеджмент). За два года в этой предметной области университет поднялся до 324-й позиции в мире и до 5-й позиции в России (после филиала НИУ ВШЭ в Санкт-Петербурге, НИУ ВШЭ, СПбГУ и РАНХиГС). ОНЦМ занимал первое место в рейтинге среди ОНЦ университета по результатам деятельности в 2017 и в 2018 гг.

Использование западных моделей управления в России показывает сложность их интеграции в российскую действительность. Системный кризис менеджмента во всех странах мира не в состоянии решать все более усложняющиеся проблемы бизнеca, что ставит перед университетами задачи коррекции своей стратегии, которая представляет совокупность действий, основанных на выверенных и далеко идущих прогнозах, в том числе развития бизнеса. При этом необходимо «точно определять смысл вещей, чтобы избавить себя от половины заблуждений» [4. - С. 23]. Коррекция стратегии, хоть и является естественным процессом, несовместима с подгоняющедогоняющим подходом.

Для достижения лидерских позиций университета необходимы два кита, на которых держится лидерство подготовки по тому или иному направлению: повышение качества образовательных программ и использование проектных методов обучения, обеспечивающих практико-ориентированный подход. В недавнем прошлом в университете реально предпринимались попытки реализации ряда отдельных перспективных проектов. Анализ этих попыток показал, что после импульсивных решений об их запуске они благополучно уходили в 
небытие. Это относится к Total Quality Management (TQM) и проектному методу.

В 1928 г. величайший русский философ Иван Ильин писал: «Качество необходимо России: волевые, знающие и даровитые люди; крепкая и гибкая организация; напряженный и добросовестный труд; выработанный первосортный продукт; высокий уровень жизни. Новая качественная эпоха нужна нашей Родине» [5].

TQM, по мнению авторов, не был в полной мере реализован в нашей среде под валом спонтанно возникающих параметров стремления РЭУ им. Г. В. Плеханова к высотам рейтингов, которые нужно было достигать «на бегу» [9. - С. 81-85]. При этом мы упустили из вида, что стратегическое управление качеством - это одновременно и философия организации, и процесс, в котором участвуют все сотрудники, проявляя ответственность за создание непрерывно совершенствующегося университета и его корпоративной культуры. Не сумев внедрить философию качества, мы утрачиваем контроль над процессами и не обеспечиваем удовлетворенность потребителя.

Качество - это то, что мы делаем, а не то, что показываем $в$ рейтингах. Общество считает образование качественным, если управленцы не допустили кризис, а инженеры - технологических катастроф. Студент как основной потребитель образования считает его качественным, если, получив диплом, он может устроиться на высокооплачиваемую должность. Практически утратив преимущество советского образования, мы, собственно говоря, не достигли уровня качества учебных планов начала прошлого века. В частности, мы не используем в подготовке управленцев балансовый метод, который должен стать основой их подготовки. Мы же не можем представить себе подготовку инженера без курса всемирно известного сопромата.

Корни утраты стратегии качества, однако, лежат не в самом университете, а в системно-разрушительных реформах образования [7. - С. 22-31]:
- в них отсутствует единый системообразующий фактор, который должен ориентировать все элементы системы на достижение главной цели - обеспечение качества образования при минимуме непроизводительных затрат;

- Министерство науки и высшего образования Российской Федерации не мотивирует вузы к внедрению методов поступательного повышения качества своей работы, используя подход «эффективный - неэффективный вуз». Опасения вузов за некорректную оценку достижения показателей эффективности приводят к завышению результатов своей деятельности, и тут уже не до качества.

Второй из китов - проектное управление как самый перспективный способ организации управления при решении уникальных задач, который имеет тысячелетнюю историю (египетские пирамиды, Великая Китайская стена и многое другое). Именно этот подход позволяет объединить в единое целое линейные процессы и разовые инициативы. Неоднократные попытки перевести управление образовательными программами на проектный метод так и не прижились в РЭУ им. Г. В. Плеханова. Во многом это связано с тем, что административные и управленческие подразделения, которые призваны обеспечивать работу кафедр, научных и учебных лабораторий, научных школ, приняли на себя только контролирующие функции, забыв, что их задача - обеспечение деятельности основных подразделений. Все меныше работающих сотрудников и все больше проверяющих и контролирующих...

Достижение цели лидерства требует от нас нестандартных решений, которые недоступны конкурентам, использующим подходы и регламенты западного, ментально чуждого россиянам менеджмента. Стратегия прорыва должна сменить догоняющий тип поведения на принципиально новую системную философию. Очевидный аналог такой смены можно привести из недавней китайской истории, когда политика «большого скачка» Мао Цзедуна 
сменилась на прорыв четырех модернизаций Дэн Сяопина.

Таким образом, по мнению авторов, в основе прорыва в лидеры РЭУ им. Г. В. Плеханова по направлению подготовки «Менеджмент» должны лежать TQM и проектное управление.

Тактика движения к лидерству является комплексной задачей, она должна быть заложена в основном документе, регламентирующем деятельность ответственных за это структурных подразделений, т. е. в положениях об этих подразделениях.

В 2019 г. конкурентами РЭУ им. Г. В. Плеханова по среднему баллу ЕГЭ зачисленных на бюджет по направлению подготовки «Менеджмент» были НИУ «Высшая школа экономики», СПбГУ и РАНХиГС. Финансирование этих университетов находится в особых условиях (отдельная строка в бюджете) в силу их статусного положения при Администрации Президента Российской Федерации и при Правительстве Российской Федерации, а РЭУ им. Г. В. Плеханова самостоятельно решает задачи по привлечению дополнительных финансовых ресурсов. Поэтому можно дать следующие рекомендации по достижению лидерских позиций и их развитию в программах подготовки студентов по направлению «Менеджмент» [8. C. 93-95]:

1. Проводить системную пошаговую предметную аналитику действий конкурентов с предоставлением результатов ректору и заинтересованным структурным подразделениям.

2. Под руководством проректора по развитию создать постоянную проектную группу для проведения форсайта предметных областей лидерства РЭУ им. Г. В. Плеханова и на этой основе организовать группы лидерских направлений с участием директоров ОНЦ, деканов и заведующих выпускающими кафедрами.

3. Вместо морально устаревших методических комиссий факультетов и кафедр передать управление ОПОП проектным группам, включающим ответственных ад- министраторов и разработчиков от факультетов, ОНЦ, кафедр и представителей бизнеса.

4. На один год забыть про навязчивый рост проходного балла и снизить его при зачислении на первый курс, закрепив профили подготовки за выпускающими кафедрами, которые должны стать лидерами в своей предметной области.

5. Приблизиться к закрытому образовательному циклу «поступление - обучение успешное трудоустройство», используемому в СССР, через системную договорную консолидацию с работодателями, изменив практику формально-юридических процедур Центра развития карьеры. Для этого считаем возможным мобилизовать основных работодателей, с которыми у университета имеются соглашения и договоры о сотрудничестве, на проведение ими при нашей поддержке дней открытых дверей с объявлением целевых рабочих мест с перспективой будущего трудоустройства. При этом очень важно на сайте разместить фото наших «звездных» выпускников, которые были отобраны работодателями по результатам обучения по направлению «Менеджмент».

6. Используя положительный опыт создания Регионального центра профориентации и трудоустройства РЭУ им. Г. В. Плеханова на базе Земской гимназии городского округа Балашиха, инициировать создание сети таких центров профориентации в городских округах Подмосковья для максимального привлечения абитуриентов на направление подготовки «Менеджмент» с последующим их трудоустройством.

7. В профориентационный процесс включить программы массового обучения потенциальных абитуриентов на направление подготовки «Менеджмент. С этой целью можно использовать вводные лидерские курсы, такие как «Цифровой менеджмент», дающий знания об основных изменениях в организациях при внедрении цифровых технологий; о цифровых системах управления, методах дизайна цифро- 
вых бизнес-стратегий; об использовании управленческих инноваций в принятии управленческих решений, основанных на использовании технологии обработки больших данных, нейросетей и др.

8. Для продвижения программ по направлению «Менеджмент» интенсивнее использовать сайты бизнес-партнеров, а также социальные сети («ВКонтакте», Facebook, Twitter, Linkedin, Instagram, Youtube), поскольку в XXI в. социальная эволюция происходит намного стремительнее с использованием различных коммуникационных элементов [2. - С. 46].

Кроме того, следует создать привлеченными силами специалистов профориентационный интегральный кафедральнофакультетский сайт по направлению «Менеджмент», на котором представлять следующую информацию:

- состав постоянной проектно-аналитической группы управления сайтом (факультет, выпускающие кафедры, практики);

- краткую аннотацию бакалаврских и магистерских программ на двух языках с представлением академических руководителей и ведущих преподавателей;

- ссылки на примеры проектных работ студентов в рамках дисциплин менеджмента;
- консультации по выбору направления магистерской программы;

- запись на регулярные мероприятия по программам подготовки по направлению «Менеджмент», в том числе на гостевое бесплатное посещение занятия по любой дисциплине программ подготовки менеджеров;

- размещение в молодежных социальных сетях электронной брошюры и видеороликов о программах обучения по направлению «Менеджмент» на двух языках, подготовленных с использованием современного профессионального дизайна таких продуктов.

9. Усилить сотрудничество с центрами профориентации, формальными и неформальными молодежными организациями с возможностью размещения информации на их ресурсах или принятых у них каналах коммуникаций (например, с закрытыми сообществами в социальной сети «ВКонтакте»).

При этом во главе угла в качестве миссии должна стоять подготовка специалистов по менеджменту, способных избавиться от засилья вредоносного для России либерального направления в затухающей экономике, ибо ленинского определения «Политика - это концентрированное выражение экономики» никто не отменял.

\section{Список литературы}

1. Бабынина Л. С. Развитие теории менеджмента // Научные стремления. Общество с ограниченной ответственностью «Лаборатория интеллекта» (Минск). - 2019. - № 25. C. 20-23.

2. Бабынина Л. С. Теоретические подходы к эффективности менеджмента // Современная экономика: концепция и модели инновационного развития : материалы VIII Международной научно-практической конференции. 19-20 февраля 2016 г. : в 2 кн. М. : ФГБОУ ВО «РЭУ им. Г. В. Плеханова, 2016. - Кн. 1.

3. Грудзинский А. О., Чупрунов Е. В. Организационные изменения университета для достижения стратегической цели развития // Высшее образование в России. - 2016. № 3 (199). - С. 117-123.

4. Декарт Р. Рассуждение о методе с приложениями. Диоптрика. Метеоры. Геометрия. M. : АН СCCP, 1953.

5. Ильин И. А. Спасение в качестве [Электронный ресурс]. - URL: https:// maxpark.com/community/politic/content/1647481 (дата обращения: 07.12.2018). 
6. Калинина И. А., Карасев П. А., Кулапов М. Н., Скоробогатых И. И. РЭУ им. Г. В. Плеханова как конкурентоспособный университет будущего // Вестник Российского экономического университета имени Г. В. Плеханова. - 2017. - № 6 (96). - С. 5-14.

7. Камынина Н. Р., Грудзинский А. О. Россия в Болонском процессе: цель - повышение конкурентоспособности высшего образования // Высшее образование в России. - 2017. № 8-9. - C. 22-31.

8. Кулапов М. Н., Масленников В. В., ШкляеВ А. Е. Образовательно-научный центр «Менеджмент» как управленческая инновация: опыт и проблемы // Вестник Российского экономического университета имени Г. В. Плеханова. - 2017. - № 1 (91). - С. 93-104.

9. Лыкова С. А., Кузнецова Н. В. Роль концепщии ТQМ в повышении эффективности функционирования организации // Современный менеджмент: теория и практика : материалы III Всероссийской научно-практической конференции, 28-29 марта 2018 г. / под общей редакцией Н. В. Кузнецовой. - Магнитогорск : Изд-во Магнитогорского гос. технического ун-та им. Г. И. Носова, 2018.

10. Путин поручил создать 15 научно-образовательных центров мирового уровня к 2024 году [Электронный ресурс]. - URL: http://tass.ru/nauka/5182137 (дата обращения: 07.02.2019).

\section{References}

1. Babynina L. S. Razvitie teorii menedzhmenta [Development of Management Theory]. Nauchnye stremleniya. Obshchestvo s ogranichennoy otvetstvennostyu «Laboratoriya intellekta» [Scientific Aspirations. Publisher "Laboratory of Intelligence"] (Minsk), 2019, No. 25, pp. 20-23. (In Russ.).

2. Babynina L. S. Teoreticheskie podkhody $\mathrm{k}$ effektivnosti menedzhmenta [Theoretical Approaches to the Effectiveness of Management]. Sovremennaya ekonomika: kontseptsiya $i$ modeli innovatsionnogo razvitiya, materialy VIII Mezhdunarodnoy nauchno-prakticheskoy konferentsii. 1920 fevralya $2016 \mathrm{~g}$. [Modern Economics: the Concept and Model of Innovative Development, Proceedings of the 8 International Scientific and Practical Conference. February 19-20, 2016], in 2 books. Moscow, FGBOU VO «REU im. G. V. Plekhanova, 2016, book 1. (In Russ.).

3. Grudzinskiy A. O., Chuprunov E. V. Organizatsionnye izmeneniya universiteta dlya dostizheniya strategicheskoy tseli razvitiya [Organizational Changes of the University to Achieve the Strategic Goal of Development]. Vysshee obrazovanie v Rossii [Higher Education in Russia], 2016, No. 3 (199), pp. 117-123. (In Russ.).

4. Descartes R. Rassuzhdenie o metode s prilozheniyami. Dioptrika. Meteory. Geometriya [Discourse on the Method with Applications. Dioptrics. Meteors. Geometry]. Moscow, USSR Academy of Sciences, 1953. (In Russ.).

5. Ilin I. A. Spasenie v kachestve [Rescue in Quality] [E-resource]. (In Russ.). Available at: https://maxpark.com/community/politic/content/1647481 (accessed 07.12.2018).

6. Kalinina I. A., Karasev P. A., Kulapov M. N., Skorobogatykh I. I. REU im. G. V. Plekhanova kak konkurentosposobnyy universitet budushchego [Plekhanov Russian University of Economics as a Competitive University of a Future]. Vestnik Rossiyskogo ekonomicheskogo universiteta imeni G. V. Plekhanova [Vestnik of the Plekhanov Russian University of Economics], 2017, No. 6 (96), pp. 5-14. (In Russ.).

7. Kamynina N. R., Grudzinskiy A. O. Rossiya v Bolonskom protsesse: tsel - povyshenie konkurentosposobnosti vysshego obrazovaniya [Russia in the Bologna Process: the Goal is to Increase the Competitiveness of Higher Education]. Vysshee obrazovanie $v$ Rossii [Higher Education in Russia], 2017, No. 8-9, pp. 22-31. (In Russ.).

8. Kulapov M. N., Maslennikov V. V., Shklyaev A. E. Obrazovatelno-nauchnyy tsentr «Menedzhment» kak upravlencheskaya innovatsiya: opyt i problemy [Education and Research 
Center 'Management' as Managerial Innovation: Experience and Challenges]. Vestnik Rossiyskogo ekonomicheskogo universiteta imeni G. V. Plekhanova [Vestnik of the Plekhanov Russian University of Economics], 2017, No. 1 (91), pp. 93-104. (In Russ.).

9. Lykova S. A., Kuznetsova N. V. Rol kontseptsii TQM v povyshenii effektivnosti funktsionirovaniya organizatsii [The Role of the TQM Concept in Improving the Functioning of the Organization]. Sovremennyy menedzhment: teoriya i praktika, materialy III Vserossiyskoy nauchno-prakticheskoy konferentsii, 28-29 marta 2018 g. [Modern Management: Theory and Practice. Materials of the 3th All-Russian Scientific and Practical Conference, March 28-29, 2018], edited by N. V. Kuznetsova. Magnitogorsk, Izd-vo Magnitogorskogo gos. tekhnicheskogo un-ta im. G. I. Nosova, 2018. (In Russ.).

10. Putin poruchil sozdat 15 nauchno-obrazovatelnykh tsentrov mirovogo urovnya $\mathrm{k}$ 2024 godu [Putin Ordered the Creation of 15 World-Class Research and Educational Centers by 2024] [E-resource]. (In Russ.). Available at: http://tass.ru/nauka/5182137 (accessed 07.02.2019).

\section{Сведения об авторах}

\section{Михаил Николаевич Кулапов}

доктор экономических наук, руководитель научной школы «Управление человеческими ресурсами» РЭУ им. Г. В. Плеханова.

Адрес: ФГБОУ ВО «Российский экономический университет имени Г. В. Плеханова», 117997,

Москва, Стремянный пер., д. 36.

E-mail: Kulapov.MN@rea.ru

\section{Валерий Владимирович Масленников}

доктор экономических наук, главный научный сотрудник ОНЦМ

РЭУ им. Г. В. Плеханова.

Адрес: ФГБОУ ВО «Российский экономический университет имени Г. В. Плеханова», 117997,

Москва, Стремянный пер., д. 36.

E-mail: Maslennikov.VV. @rea.ru

Максим Александрович Пономарев

кандидат экономических наук, декан

факультета менеджмента

РЭУ им. Г. В. Плеханова.

Адрес: ФГБОУ ВО «Российский экономический университет имени Г. В. Плеханова», 117997,

Москва, Стремянный пер., д. 36.

E-mail: Ponomarev.MA@rea.ru

\section{Лилия Сергеевна Бабынина}

доктор экономических наук, главный

научный сотрудник ОНЦМ

РЭУ им. Г. В. Плеханова.

Адрес: ФГБОУ ВО «Российский экономический университет имени Г. В. Плеханова», 117997,

Москва, Стремянный пер., д. 36.

E-mail: Babynina.LS@rea.ru

\section{Information about the authors}

\section{Mikhail N. Kulapov}

Doctor of Economics, Head of Scientific School of the "Human Resource Management" of the PRUE.

Address: Plekhanov Russian University of Economics, 36 Stremyanny Lane, Moscow, 117997, Russian Federation. E-mail: Kulapov.MN@rea.ru

\section{Valery V. Maslennikov}

Doctor of Economics, Chief Researcher of the Educational and Scientific Center "Management" of the PRUE.

Address: Plekhanov Russian University of Economics, 36 Stremyanny Lane, Moscow, 117997, Russian Federation. E-mail: Maslennikov.VV. @rea.ru

\section{Maxim A. Ponomarev}

PhD, Dean of the Faculty of Management of the PRUE.

Address: Plekhanov Russian University of Economics, 36 Stremyanny Lane,

Moscow, 117997,

Russian Federation.

E-mail: Ponomarev.MA@rea.ru

\section{Liliya S. Babynina}

Doctor of Economics, Chief Researcher of the Educational and Scientific Center "Management" of the PRUE.

Address: Plekhanov Russian University of Economics, 36 Stremyanny Lane, Moscow, 117997, Russian Federation. E-mail: Babynina.LS@rea.ru 